\title{
Estudo socioterritorial e investimentos públicos: processo de alocação de recursos do orçamento participativo em Serra/Es*
}

Cristiano das Neves Bodart

\section{Introdução}

Diversos estudos em torno das práticas de orçamentos participativos (OP) têm sido desenvolvidos no Brasil nos últimos anos. De maneira geral, trata-se de uma gestão pública caracterizada pela participação direta da sociedade na gestão dos recursos municipais. A participação se dá, geralmente, por meio da deliberação social sobre parte dos investimentos públicos, quase sempre obras de infraestrutura.

A questão central deste trabalho é averiguar se a prática de OP é capaz de romper com o "princípio de causação circular"” e promover uma alocação das obras de infraestrutura mais justa, atendendo prioritariamente a população de baixo status social ou as áreas urbanas mais carentes de infraestrutura.

A problemática desta pesquisa foi diretamente influenciada por dois trabalhos desenvolvidos anteriormente no Brasil. O primeiro deles foi a tese de doutoramento de Denise Cunha Tavares Terra (2007), sob o título de Uma leitura espacial da apropriação desigual das rendas petroliferas em Campos dos Goytacazes, que 
abordou de forma instigante a lógica alocativa das rendas petrolíferas em Campos dos Goytacazes, evidenciando a existência de uma "causação circular" na alocação dos recursos advindos das rendas petrolíferas. O segundo trabalho foi a pesquisa desenvolvida por David Michael Vetter e Rosa Maria Massena, apresentada em artigo, de 1981, intitulado Quem se apropria dos benefícios líquidos dos investimentos do Estado em infraestrutura urbana? Uma teoria da causação circular. Neste artigo Vetter e Massena apontaram a existência do princípio de causação circular na alocação dos investimentos destinados à distribuição de água e esgoto no Rio de Janeiro.

Neste artigo, buscando averiguar se a prática do OP seria capaz de romper com o "princípio da causação circular" na alocação das obras de infraestrutura urbana, foi tomada como estudo de caso a experiência de participação popular na gestão pública no município de Serra/ES (1997 - 2008), denominada pelo poder público local como Orçamento Participativo.

O presente artigo está dividido em três partes, além desta introdução e de uma conclusão. A primeira parte tem como objetivo apontar o alinhamento teóricometodológico do presente estudo, buscando identificar as principais contribuições teóricas. Nesse primeiro momento são delimitados teoricamente conceitoschave para a produção desta pesquisa, tais como espaço urbano, causação circular, renda real, entre outros, assim como discutidas teoricamente as questões relacionadas à participação popular na gestão pública, especialmente por meio das práticas de orçamentos participativos. Buscamos, com isso, compreender as principais características do OP, principalmente aquelas relacionadas à redistribuição de renda.
A segunda e a terceira seção estão centradas no estudo de caso. $\mathrm{Na}$ segunda é realizada uma breve caracterização do município de Serra/ES e apresentada a estrutura funcional do OP de Serra/ES. $\mathrm{Na}$ terceira seção são apresentados os procedimentos metodológicos adotados para este estudo, bem como os resultados alcançados.

\section{$\mathrm{O}$ poder público e a produção do espaço urbano}

Para compreender a relação entre a alocação dos investimentos públicos em obras de infraestrutura e a construção socioespacial intraurbana, torna-se necessário, inicialmente, definir o conceito de espaço urbano adotado no presente trabalho.

Partimos da colaboração de Corrêa (1993, p. 7; 2005, p. 145), que afirma que o espaço urbano capitalista caracteriza-se como simultaneamente fragmentado e articulado, tratando-se de um espaço produzido pela sociedade e reflexo desta. De acordo com Corrêa, o espaço caracteriza-se como fragmentado por ser fortemente dividido em áreas residenciais segregadas, fruto da complexa estrutura social (CORRÊA, 1992, p. 7).

O espaço urbano é o local onde se "concentram as mais poderosas forças sociais, com as quais se articulam e desenvolvem as estruturas de dominação e apropriação" (IANNI, 2004, p. 155); assim como as tensões e contradições, germinando movimentos sociais e protestos de grupos e classes sociais subalternos, caracterizando-se como o espaço das contradições e mutações, da integração e da fragmentação, da inclusão e da exclusão, da riqueza e da pobreza, reflexo das ações do presente e do passado. (CORRÊA, 1992, p. 8; 2005, p. 148). 
Os atores que modelam e organizam o espaço urbano são diversos, como, por exemplo, os proprietários dos meios de produção, proprietários de terras, empresas imobiliárias e de construção e o Estado (CorrêA, 2005, p. 122). Cada um desses agentes possui estratégias próprias, desencadeando conflitos - especialmente pelos três primeiros - que são, de acordo com Corrêa, em maior ou menor grau, resolvidos pela intervenção do Estado.

A necessidade da intervenção do poder público se dá devido à rápida concentração da produção e da população nas áreas urbanas, o que gera grande demanda por bens e serviços coletivos, uma vez que a alocação desses bens e serviços ou o controle desses custos não podem ser efetuados no mercado (VeTter, Pinto, Friedrich e Massena, 1981, p. 5).

O Estado pode ou não reforçar a segregação espacial, aumentando ou diminuindo a distância social entre pobres e ricos por meio da provisão diferenciada de serviços e equipamentos públicos (Marques, 2000). Destacam diversos autores (HARVEY,1980; Vetter, Massena e Rodrigues, 1979) que a alocação dos recursos públicos produz impactos diretos na redistribuição ou na concentração da renda, daí a importância de nos atentarmos para o papel do poder público na produção do espaço urbano, seja pela sua ação ou ausência.

Terra (2007, p.32), ao analisar os estudos de Vetter e Massena (1979; 1981), afirma que tais autores apresentam uma alternativa à teoria neoclássica do equilíbrio espacial, destacando a teoria da "causação circular" como a mais apropriada para o estudo dos impactos distributivos dos investimentos do Estado.

O conceito do "princípio da causação circular" envolve uma constelação circular de forças que, para Myrdal (1968, p. 32), "tendem a agir e a reagir interdependentemente, de sorte a manter um país pobre em estado de pobreza". Aplicando esse conceito à cidade, nota-se que áreas dotadas de infraestrutura - áreas centrais ou em destaque - tendem a receber mais infraestrutura pública (devido à lógica eleitoreira e clientelista), além de investimentos privados (devido à lógica capitalista). $\mathrm{O}$ inverso ocorre em áreas não dotadas de infraestrutura, ou seja, as áreas onde existem menos infraestruturas urbanas, geralmente

"O Estado pode ou não reforçar a segregação espacial, aumentando ou diminuindo a distância social entre pobres e ricos por meio da provisão diferenciada de serviços e equipamentos públicos”

periféricas, continuam a não recebê-las. É muito comum no país, por exemplo, uma cidade possuir ruas ainda não pavimentadas e o poder público optar por (re)pavimentar ruas e avenidas já pavimentadas. Essa tendência de “causação circular” foi evidenciada nos estudos de caso de Vetter, Massena e Rodrigues (1979), Vetter e Massena (1981), e de Terra (2007), ao estudarem a alocação 
dos investimentos públicos em água e esgoto no Rio de Janeiro, entre 1975 a 1977.

Terra (2007, p. 207), ao analisar, entre outros aspectos, a distribuição espacial das obras públicas na cidade de Campos dos Goytacazes/RJ, destacou que "os espaços habitados pela população de rendas alta e média alta receberam proporcionalmente mais recursos que os espaços onde reside a população de menor poder aquisitivo", evidenciando a existência do princípio de "causação circular" na prática alocativa daquele município.

A provisão de bens públicos, além de influenciar a construção do espaço urbano, afeta diretamente a renda real dos indivíduos. De acordo com Harvey (1980, p.48) os "mecanismos ocultos" ${ }^{2}$ " de redistribuição de renda num sistema urbano tendem a ampliar as desigualdades sociais, ao invés de reduzi-las. Para embasar tal argumentação, esse autor adotou a definição de renda real de Titmuss (HARVEY, 1980 apud Titmuss, 1962, p.34), que será, neste trabalho, utilizada, sendo assim definida:

A renda real é a soma algébrica do valor de mercado nos direitos exercidos no consumo e da troca no valor do suprimento de direitos de propriedade entre o começo e o fim do período em questão (HARveY, 1980, p.41).

Harvey (1980, p.42) acrescenta que “o poder sobre os recursos escassos da sociedade não pode ser determinado independentemente da acessibilidade aos recursos e seus preços". Um indivíduo, devido à alocação de uma dada obra de infraestrutura, pode ampliar ou reduzir o valor de seu imóvel, por exemplo, bem como maximizar ou minimizar a capacidade de acessibilidade aos bens públicos, como educação, saúde, transporte, bens culturais e de lazer. Por tanto, a alocação de obras públicas afetará diretamente a renda real do indivíduo. A questão que se levanta é que mudanças na forma espacial da cidade, e consequentemente nos processos sociais, provocam mudanças na renda do indivíduo (Harvey, 1980, p. 42).

Para uma compreensão dos mecanismos de ação do Estado em um processo de redistribuição de renda real, buscou-se as principais ideias traçadas por Harvey (1980), baseadas na acessibilidade, proximidade e exteriorização.

Para Harvey a acessibilidade interfere na renda real do indivíduo, como, por exemplo, a acessibilidade à oportunidade de emprego, de recursos e serviços de bemestar. Uma obra, dependendo de sua acessibilidade, pode ampliar a renda real de um indivíduo. Harvey (1980) destaca, além do preço monetário da acessibilidade, o seu valor emocional e psicológico, que acaba, a longo prazo, transformando-se em monetário.

Outro mecanismo oculto de redistribuição destacado por Harvey é o custo da proximidade. A localização de uma obra pública, por exemplo, tende a mudar o preço da acessibilidade e o custo da proximidade (Harvey, 1980; VetTer, Massena e Rodrigues, 1979). A locação de lixões, por exemplo, tende a impor um custo à população por suas proximidades, bem como lhe render maiores gastos com a saúde (com remédios e transporte para se deslocar ao posto de saúde) e/ou a desvalorização de seu imóvel, reduzindo dessa forma sua renda real.

Por fim, Harvey apresenta a ação da exteriorização sobre a renda real, afirmando que "as exteriorizações podem ser vistas como custos ou benefícios conforme o produtor ou o consumidor seja afetado, e segundo a natureza do efeito" (HARveY, 1980, p.46). 
Harvey (1980, p.61) afirma que é teoricamente possível, pela atividade política e pela barganha, conseguir uma alocação equilibrada de todos os bens e serviços mistos em uma população espacialmente distribuída. No entanto, para isso, seria necessário um processo político organizado que facilitasse a "igualdade de barganha" entre grupos com interesses diferentes, mas internamente homogêneos. Seria o OP esse processo organizado apontado por Harvey?

Diversos estudos empíricos apontam experiências brasileiras bem-sucedidas em relação a uma alocação mais equilibrada e mais justa dos investimentos públicos por meio da prática do OP. Entre esses estudos destacam-se as análises de Aldamir Marquetti, Roberto Pires, Geraldo Adriano de Campos, Aldecy José G. de Moraes, reunidas na obra "Democracia Participativa e redistribuição: análise e experiências de orçamento participativo" (2008), e o trabalho organizado por Leonardo Avritzer e Zander Navarro, intitulado $A$ inovação democrática no Brasil (2003).

A descentralização dos recursos públicos e a maior autonomia dos municípios brasileiros criaram um cenário propício ao desenvolvimento de uma democracia mais participativa que, de acordo com Marquetti e Campos (2008), Souza (2006) e Correia (2003), possibilitou o desenvolvimento de experiências bem-sucedidas de participação popular na administração dos recursos públicos, como é o caso do $\mathrm{OP}$ de Porto Alegre/RS, de Belo Horizonte/ MG; e de outras bem discutidas, como é o caso de Belém/PA. É importante apreender que a implantação, no Brasil, das instituições democráticas híbridas (onde simultaneamente são adotados aspectos da democracia representativa e participativa, ou direta), especialmente os OP, ocorreu em ritmo, intensidade e formatos variados (CunHa, 2007, p. 30).

De maneira geral, o Orçamento Participativo é um mecanismo de democratização da política orçamentária estatal, reunindo os cidadãos em assembleias públicas nas quais avaliam a gestão municipal, elaboram propostas de acordo com suas demandas e deliberam sobre uso e aplicação dos recursos públicos e os dirigentes estatais executam a vontade popular (Gugliano, 2007).

O OP se apresenta como uma forma institucional que envolve a partilha de espaços de deliberação entre representações estatais e entidades da sociedade civil, tendo como base a negociação e a parceria (Pereira, 2007, p. 339), caracterizando-se como uma estrutura aberta, em constante mutação de acordo com os formatos necessários a cada realidade ou interesse, pois sua estrutura não é fechada em modelo jurídico que vem de cima para baixo (Minghelli, 2005, p. 66). O OP é entendido como experiência de cogestão, "modelo de partilha do poder político mediante uma rede de instituições democráticas orientadas para obter decisões por deliberação, por consenso e por compromisso" (Santos, 2002, p. 525 apud Azevedo, 2005, p. 109).

Leonardo Avritzer, ao estudar os efeitos distributivos das políticas participativas no Nordeste, constatou uma correlação significativa entre as cidades com maior número de instituições participativas e as taxas de matrículas no Ensino Básico e em creches. "Nesse caso, quanto mais alta a posição de uma cidade na escala de participação, maiores são as taxas de matrículas" (Avritzer, 2007, p. 37). Esse mesmo autor observou que as cidades nordestinas de médio porte, pouco dotadas de estoque de bens públicos 
(educação e saúde), tiveram o volume desses bens ampliado, acima da média, após a implantação de políticas participativas.

\section{O orçamento participativo}

\section{de Serra/ES e sua estrutura organizacional}

O município de Serra está localizado na Região Metropolitana da Grande Vitória/ES, (ver Cartograma 1), estando sua sede distante $28 \mathrm{~km}$ da capital do Estado do Espírito Santo, Vitória, possuindo uma área de aproximadamente $553 \mathrm{Km}^{2}$ (IBGE, 2007). Limita-se ao norte com o município de Fundão, ao sul com Cariacica e Vitória, a oeste com Santa Leopoldina e a leste com o Oceano Atlântico. Está dentro de um raio de mil $\mathrm{km}$ de distância dos principais centros consumidores do país - São Paulo, Rio de Janeiro, Minas Gerais e Bahia. Sua posição geográfica privilegiada facilita o abastecimento de matéria-prima e o acesso a mercados emergentes, colocando-o como principal município industrial do estado. Com uma população estimada em 394.370 habitantes (IBGE, 2007), Serra vem se destacando como o segundo maior município em tamanho populacional, tendo apresentado, em 2006, uma taxa de crescimento demográfico de $3,53 \%$, bem acima da média nacional $(1,62 \%)$ e da média capixaba, que foi de 1,91\% no mesmo período (SERRA, 2007).

O município de Serra possuía, no ano de 2000, 118 bairros, sendo em sua maioria bairros urbanos. Porém, apenas

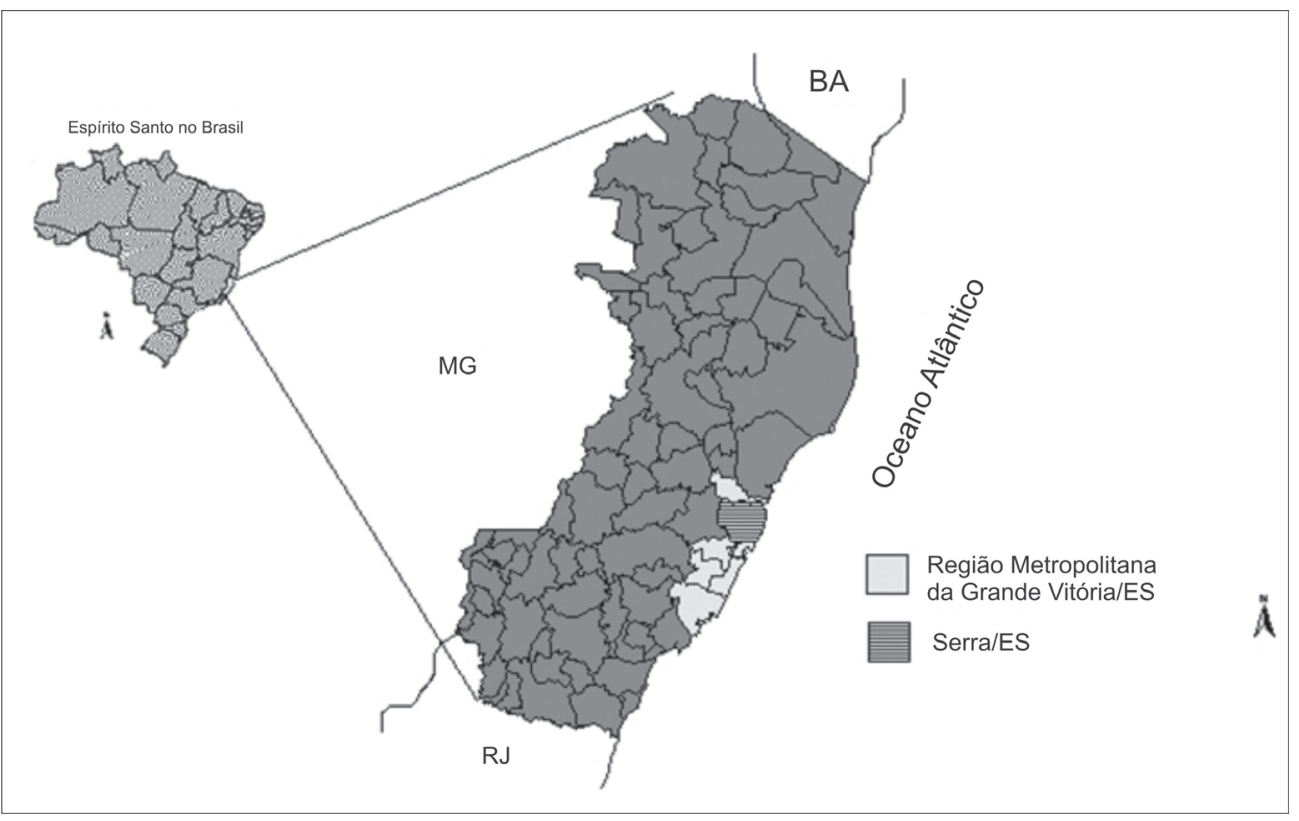

Fonte: Produzido pelo autor a partir da Base de Informações por Setor Censitário do Censo Demográfico (IBGE, 2000).

Cartograma 1: Espírito Santo com destaque para a Região Metropolitana da Grande Vitória (RMGV) e do município de Serra/ES. 
109 deles serão estudados no presente trabalho, por serem os demais rurais ou não terem dados estatísticos sobre os mesmos.

Serra possui uma estrutura associativa que teve origem ainda na década de 1970, com os movimentos de base. De acordo com entrevistas realizadas a alguns delegados e integrantes do Núcleo de Acompanhamento do OP (NAOP) de Serra, o surgimento de movimentos sociais organizados, a fim de reivindicar suas demandas, propiciou um cenário favorável ao surgimento, no início da década de 1980, da Federação das Associações de Moradores de Serra (FAMS). Tal federação tornou o município uma referência de organização popular no Estado do Espírito Santo, tendo, em 2006, 136 associações de moradores.

A principal bandeira da FAMS, na década de 1990, foi a busca pela implantação do OP em Serra/ES. O processo de elaboração de uma assembleia do orçamento público municipal ocorreu a partir da participação da sociedade civil, sendo essa regulamentada pela Lei n ${ }^{\circ}$ 1788/ 94, de iniciativa popular, dando origem à Assembleia Municipal do Orçamento (AMO). Todavia, sua oficialização não foi suficiente para a efetivação do processo, uma vez que o executivo não cumpria as metas estabelecidas pela AMO. A falta de vontade política, naquele período, inviabilizou a prática de Orçamento Participativo. Como Marquetti (2007), Boas (2007), Coêlho (2007), Marquetti e Campos (2008) e Teixeira (2003) observaram, a vontade política para a implementação do OP é de fundamental importância, e Serra não se diferenciou dessa realidade. O OP só passou a ser uma peça destacada na gestão municipal em 1997, no primeiro mandato do prefeito Sérgio Vidigal (Coligação Frente
Popular da Serra - PDT, PSB, PPS e PTB). Desde então o OP tem ocorrido sem interrupções.

Quanto à estrutura institucional do OP de Serra/ES, foi possível identificar, a partir de entrevistas a membros do NAOP, que oficialmente são participantes do OP as entidades civis organizadas como a Federação das Associações de Moradores da Serra, as associações de moradores, conselhos municipais, verea-

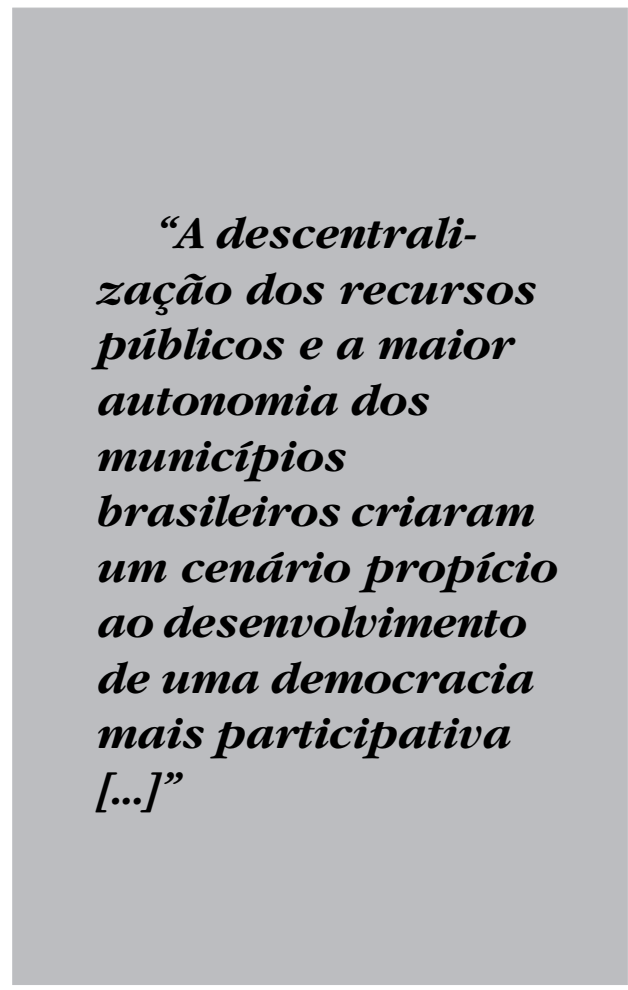

dores do município e representantes da prefeitura municipal. Inicialmente o OP é conduzido pela AMO, instituída pela lei 1788, de 1994.

A AMO é composta pela Prefeitura, Câmara de Vereadores e a FAMS, as quais atuam junto às comissões orçamentárias. A AMO é instalada anualmente, sendo eleitas pelos delegados (representantes escolhidos por cada segmento participante das 
assembleias) sua coordenação, secretaria e comissões orçamentárias. Cada uma das comissões é composta por quatro membros do movimento popular, dois vereadores e um representante da Prefeitura. As comissões são: Comissão de Critérios de Rateio; Comissão de Fiscalização e Acompanhamento; e Comissão de Organização e Comunicação. Além das assembleias regionais, são realizadas, antes dessas, as assembleias por bairro.

A organização da AMO é exemplificada pela Figura 1: de regionais mais pobres, ocorrida em 1999, como a Região Praia, em Praia I e Praia II, a Região Sede, em Sede I e Sede II (CARlos, 2007). Além dessas optou-se por subdividir a Região de CIVIT, em CIVIT I e CIVIT II, e uma reordenação de alguns bairros, dando origem à Região de Castelândia.

Para a realização de assembleias regionais, a cidade está atualmente dividida em onze regionais, como indica o Cartograma $2 .^{3}$

A coordenação do OP só pode aprimorar a metodologia distributiva,

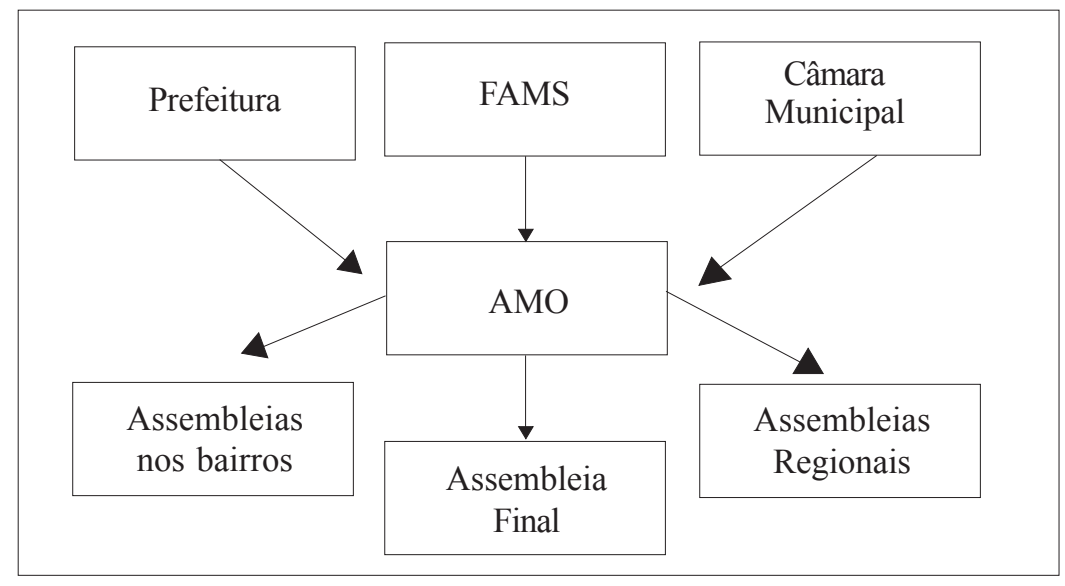

Fonte: Cartilha do Orçamento Participativo 2007 (PMS, 2007c).

\section{Figura 1: Organograma funcional do OP de Serra/ES}

Com relação à evolução do desenho institucional, este foi, ao longo do tempo, sofrendo mudanças em suas regras e métodos, buscando possibilitar uma maior participação social e um maior atendimento às regiões mais carentes (Carlos, 2007, p. 147). Afirma Carlos que tais mudanças foram ocorrendo fundamentadas no diálogo constante entre atores sociais e estatais, o que para Pires (2008, p. 57) é fundamental para a preservação da autonomia dos participantes do OP. Entre as mudanças ocorridas na estrutura do OP de Serra, está a subdivisão aumentando a complexidade operacional e a objetividade das decisões, a partir de 2000, com a criação do Núcleo de Acompanhamento do Orçamento Participativo (NAOP) e posterior divulgação dos dados do censo de 2000, realizado pelo IBGE (CARlos, 2007, p. 193).

A metodologia desenvolvida para a distribuição dos recursos entre as regionais é baseada em três índices: o primeiro é o Índice de Gestão que é composto pelos indicadores do número de matrículas nas escolas de Ensino Fundamental, volume de 
Regionais do OP

\begin{tabular}{|c|c|}
\hline & Anchieta \\
\hline & Carapina \\
\hline & Castelândia \\
\hline & CIVIT A \\
\hline & CIVIT B \\
\hline & Laranjeira \\
\hline & Praia I \\
\hline & Praia II \\
\hline & Praia III \\
\hline & Serra A \\
\hline & Serra B \\
\hline
\end{tabular}

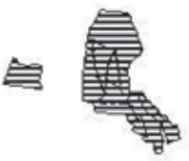

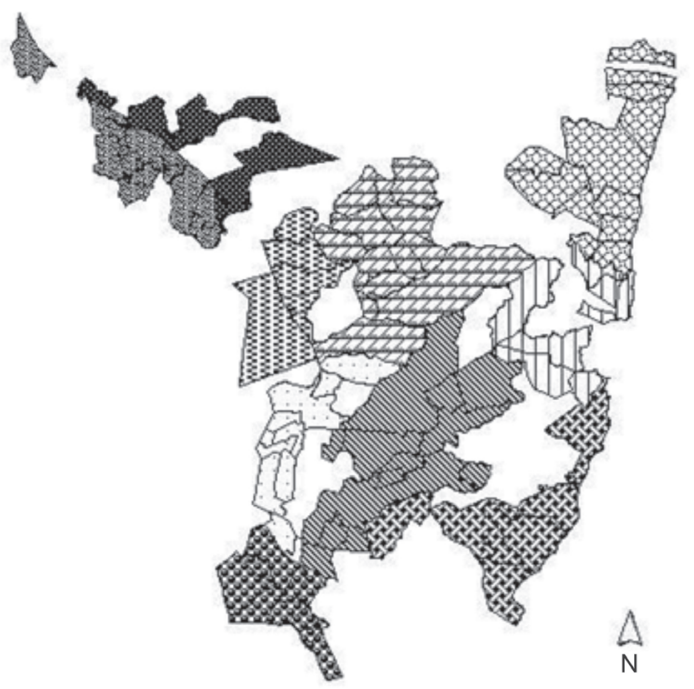

Fonte: Produzido pelo autor a partir da Base de Informações por Setor Censitário do Censo Demográfico (IBGE, 2000) e dados fornecidos pelo Núcleo de Acompanhamento do OP (PMS, 2008).

\section{Cartograma 2: Serra: Regionais do orçamento participativo}

investimentos anteriores e o número de crianças à espera de vagas no ensino infantil; o segundo é o Índice de Cidadania Participativa, que observa o número de participantes na Assembleia Municipal do Orçamento (AMO) e a adimplência de IPTU; o terceiro índice é o Índice Social, composto pelo tamanho da população e pela taxa de analfabetismo entre os indivíduos acima de 15 anos. No Índice de Gestão são beneficiadas as regionais (recebendo maior volume de investimento) que apresentarem o maior número de matrículas no Ensino Fundamental e na espera de vagas no ensino infantil, e um menor volume de investimentos nos anos anteriores. No Índice de Cidadania Participativa, buscase dotar de mais investimentos as regionais que apresentam maior participação na AMO e maior adimplência de IPTU. O terceiro critério - Índice Social - busca beneficiar as regionais dotadas de maior volume populacional e de elevadas taxas de analfabetismo entre indivíduos de mais de 15 anos.

Ao analisar a evolução dos valores destinados ao OP de Serra foi evidenciado que, proporcionalmente à evolução da receita e à capacidade de investimento municipal, esse valor já foi maior, embora 
seu valor absoluto tenha se ampliado a cada ano, como é possível observar nas figuras 2 e 3 :

A Figura 2 nos possibilita observar um incremento constante nos valores destinados ao OP entre o período de 1998 a 2008. A Figura 3 permite constatar que tal incremento não foi proporcionalmente acompanhado pela evolução da capacidade de investimento municipal.

O município de Serra se destaca entre os demais municípios capixabas como o segundo maior em volumes de investimentos, por isso é tão importante avaliarmos a alocação de tais investimentos. A Tabela 1 apresenta um ranking dos 10 maiores municípios investidores no Espírito Santo.

Nota-se que a capacidade de investimento do município de Serra, em 2008, só ficou abaixo da Capital do estado, Vitória. O terceiro maior município investidor não chegou a apresentar 40\% do volume de investimentos de Serra.

\section{O processo de alocação de recursos do orçamento participativo em Serra/ES (1998 - 2008)}

O procedimento metodológico do presente capítulo estrutura-se em três seções: i) a primeira destinada à regionalização de Serra com base em indicadores selecionados; ii) a identificação da espacialização dos investimentos públicos per capita em obras de infraestrutura, destinados ao OP sobre as regionais, comparando-as aos indicadores selecionados, por regional; iii) a identificação da lógica alocativa de tais obras entre os bairros, também confrontando essa lógica com os indicadores selecionados. Desta forma busca-se analisar, na primeira seção, a capacidade redistributiva do instrumento de gestão pública praticado em Serra denominado OP, assim como, na segunda seção, o potencial redistributivo da deliberação social. Para a operacionalização intrarregional das análises, foi utilizado
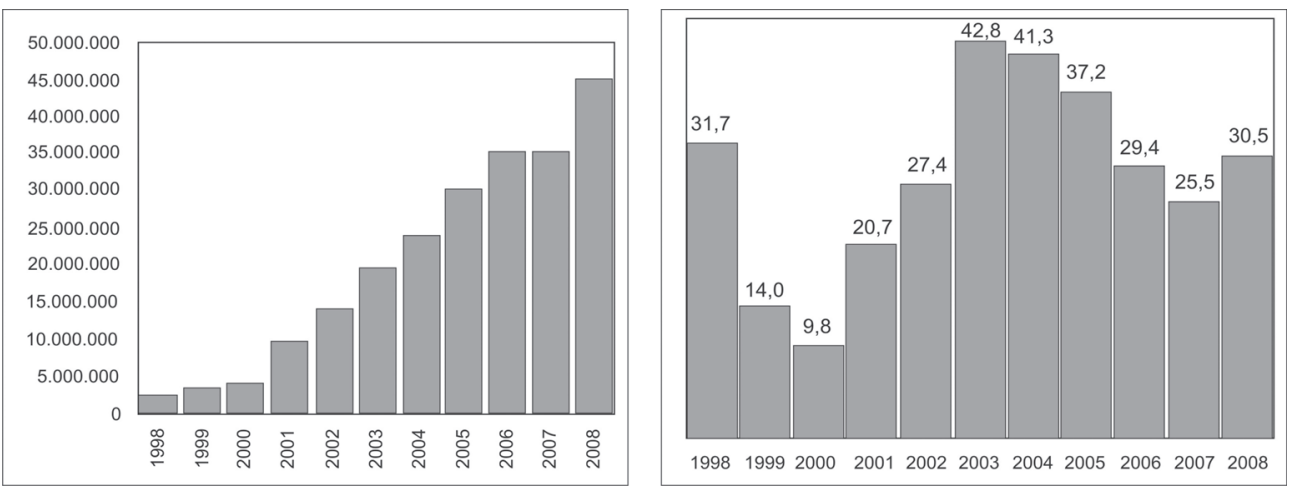

Fonte: Núcleo de Acompanhamento do OP (PMS, 2008; 2011); SERRA. Perfil Socioeconômico (2007; 2008).

Figura 2: Evolução dos valores destinados ao OP de Serra/ES (1998-2008). Figura 3: Participação dos valores destinados a obras do OP de Serra em seus investimentos totais (1998-2008). 
Tabela 1: Investimento total dos 10 maiores municípios investidores do Espírito Santo, em 2008.

\begin{tabular}{l|l|l}
\hline Posição & Município & Investimento - R\$ \\
\hline 1 & Vitória & 235.622 .363 \\
2 & Serra & 137.386 .318 \\
3 & Cariacica & 53.961 .389 \\
4 & Vila Velha & 51.907 .886 \\
5 & Aracruz & 35.948 .208 \\
6 & Linhares & 30.169 .995 \\
7 & Cachoeiro de Itapemirim & 18.848 .398 \\
8 & Colatina & 18.803 .621 \\
9 & Anchieta & 16.152 .647 \\
10 & Viana & 13.374 .626 \\
\hline
\end{tabular}

Fonte: FUTURA. Anuário dos Municípios Capixabas 2008.

o software ArcView 3.2. para a espacialização das variáveis utilizadas na análise sobre a malha urbana de Serra.

\section{Regionalização do espaço urbano de Serra/ES com base em indica- dores selecionados}

O município de Serra/ES possui duas regionalizações utilizadas pelo poder público local. Uma delas é a regionalização administrativa e a regionalização do Orçamento Participativo, mas para a efetivação da proposta deste artigo foram criadas novas regionalizações, começando por indicadores selecionados, a partir do censo demográfico realizado pelo Instituto Brasileiro Geográfico e Estatístico (IBGE) no ano de $2000^{4}$. São eles:

- Percentual de chefe de domicílio com renda de até dois salários mínimos ${ }^{5}$;

- Percentual de analfabetismo entre a população de 15 anos ou mais;

- Proporção de domicílio inadequado ${ }^{6}$;

- Proporção de domicílio com esgoto inadequado ${ }^{7}$.
A partir dos dados referentes aos bairros de Serra/ES foram identificados os indicadores selecionados das 11 regionais do OP (suas médias ponderadas). O objetivo é identificar as áreas de baixo status, médio baixo status, médio alto status e de alto status do município, tanto na escala regional quanto em uma menor escala (bairros). A partir dos dados das regionais do OP buscou-se encontrar os quartis de cada indicador social em análise. $\mathrm{O}$ objetivo é classificar as regionais do OP como baixo status, médio baixo, médio alto $e$ alto status. Desta forma, as regionais que se localizarem no primeiro quartil da renda média dos chefes de domicílio, por exemplo, serão identificadas como sendo de baixo status, e aquelas que se localizarem no último quartil estarão sendo classificadas como alto status.

Uma vez identificado às áreas sociais em grupos de status social, torna-se possível analisar se o poder público municipal tem, por meio da prática de OP, beneficiado (por meio da alocação dos investimentos públicos destinados ao OP) as áreas de alto 
status, mantendo assim o "princípio de causação circular", ou se tem promovido redistribuição de renda real. Os dados foram exportados para o Software ArcView $3.2^{8}$ a fim de produzir cartogramas que proporcionassem uma visualização espacial das áreas de status sociais, sobrepostos ao volume dos investimentos destinados ao OP de Serra no período de 1998 a 2008, também espacializados.

Para a efetivação da análise alocativa das obras de infraestrutura destinadas ao OP, foi necessário utilizar duas unidades espaciais de análise: a "região" e o "bairro". Isso se dá por duas razões básicas: i) no recorte "regional", a alocação dos investimentos públicos em uma prática de OP se dá, geralmente, por critérios técnicos, desta forma a análise da espacialização dos investimentos entre as regionais da cidade evidenciará a lógica alocativa do instrumento (OP) e não necessariamente da deliberação social; ii) o recorte "bairro" é utilizado como unidade de análise para averiguar a lógica alocativa da deliberação social, uma vez que é na plenária regional (fóruns públicos) que os cidadãos estarão decidindo em qual bairro - da região - serão alocados os investimentos em infraestrutura, bem como a tipologia das obras que serão executadas.

Ao comparar a classificação dos bairros por status social notou-se que existem bairros de alto status em regionais classificadas como de baixo status e vice versa. Desta forma o investimento público pode estar sendo alocado em bairros de alto status localizados em regionais de baixo status, indicando a necessidade de averiguar a alocação das obras públicas do OP também na escala intrarregional.

É importante destacar que foram considerados, para as análises deste trabalho, apenas os investimentos realizados, o que justifica termos nos limitado ao período de 1998 a 2008, uma vez que, de acordo com a NAOP, apenas 3,3\% das obras do OP de 2009 foram concluídas ${ }^{10}$.

\section{Avaliação do potencial redistri- butivo do critério de rateio do OP de Serra /ES}

Afirmam os entrevistados, membros da NAOP, que o OP de Serra objetiva, a partir de seu critério técnico de rateio, beneficiar prioritariamente os bairros mais carentes (onde reside maior proporção de pobreza e de menos infraestrutura). Porém, na construção dos indicadores utilizados para rateio dos investimentos do OP entre as regionais, não tem sido utilizada a proporção de chefes de domicílio com renda de até dois salários mínimos. Se o objetivo do critério de rateio dos investimentos do OP de Serra/ES é buscar atender prioritariamente as regionais onde há uma maior proporção de chefes de domicílios possuidores de menor renda mensal, este objetivo não foi atingido ao longo dos primeiros 11 anos de prática. Assim, inicialmente foi averiguado se as regionais classificadas neste trabalho como áreas de baixo status (as regionais de menor rendimento mensal dos chefes de domicílio) foram as que receberam maiores investimentos per capita durante o período em estudo.

Partindo do pressuposto de que as regionais concentradoras de chefes de domicílios com renda de até dois salários mínimos compõem as áreas mais carentes de intervenção do estado para a ampliação da renda real desses indivíduos, buscou-se averiguar se tais áreas são as mais beneficiadas pelo critério de rateio dos investimentos do OP.

O Cartograma 3 possibilita identificar espacialmente que duas das quatro 


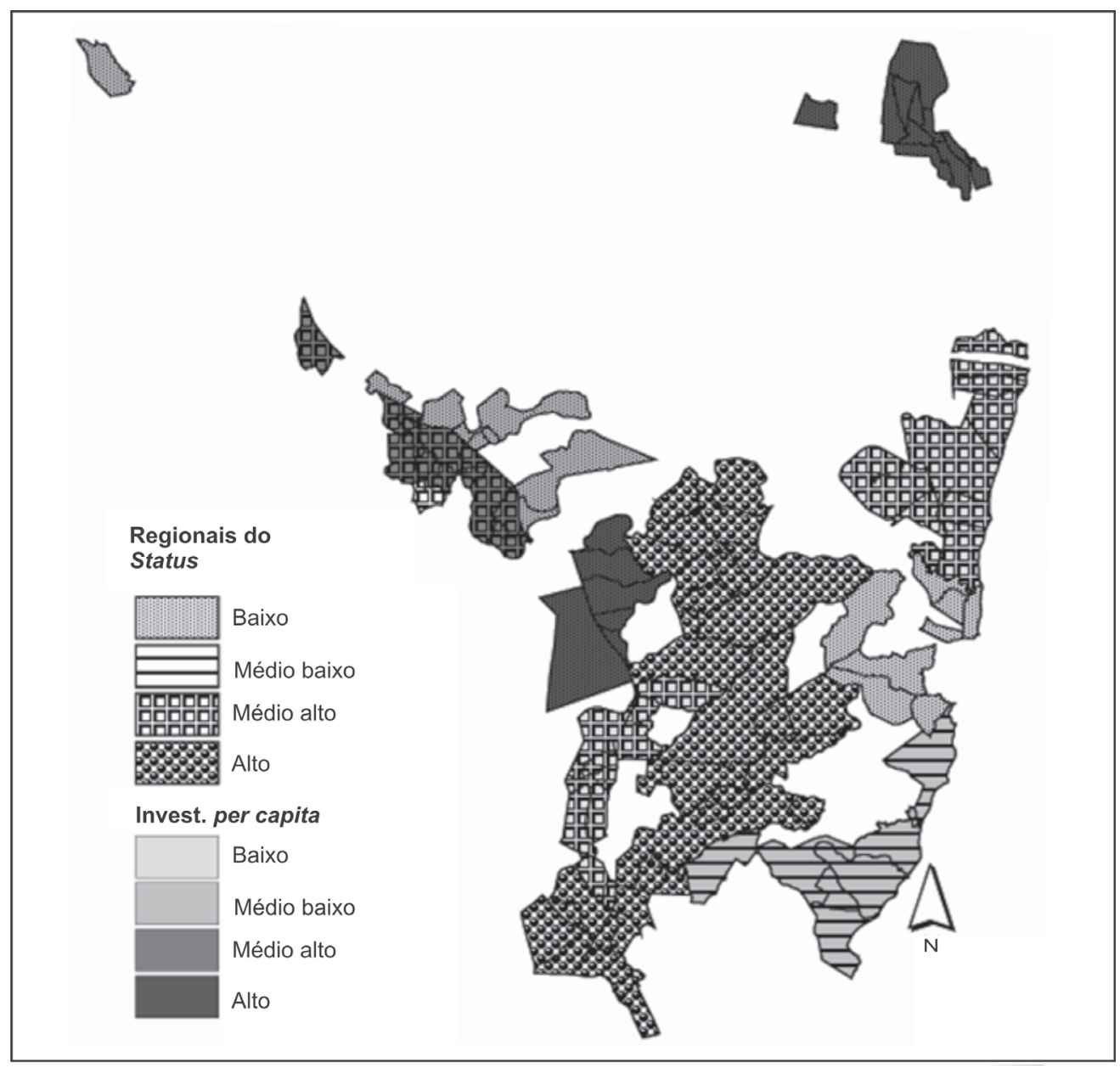

Fonte: Produzido pelo autor a partir da Base de Informações por Setor Censitário do Censo Demográfico (IBGE, 2000) e dados fornecidos pelo Núcleo de Acompanhamento do OP (PMS, 2008; 2011).

Cartograma 3: Serra: Distribuição espacial dos investimentos per capita destinados ao OP durante o período de 1998 a 2008 e proporção de chefes de domicílio com renda de até dois salários mínimos por regional do OP

regionais que foram classificadas como baixo status (com base na identificação dos quartis obtida dos percentuais de concentração de chefe de domicílio com renda de até dois salários mínimos) receberam alto investimento per capita. Outra constatação observada foi que nenhuma regional de alto status, a partir da presente metodologia, demonstrou ter recebido elevado investimento per capita, pelo contrário, recebeu baixo investimento per capita. Desta forma pode-se, mais uma vez, afirmar que o critério utilizado para distribuir os investimentos pelas regionais caracteriza-se como instrumento capaz de romper com a "causação circular", pelo menos nas duas análises realizadas até o momento. 
Pelo fato dos investimentos destinados à prática do OP em Serra/ES serem voltados à realização de obras de infraestrutura, torna-se necessário observar se tais investimentos buscam atender prioritariamente as áreas onde existe maior concentração de domicílios inadequados e sem esgoto adequado. Observou-se que das três regionais classificadas como baixo status, a partir (último quartil, área de maior concentração) da proporção de domicílios com esgoto inadequado, duas delas receberam maior investimento per capita. Observa-se também que todas as regionais classificadas como alto status receberam baixo investimento per capita.

Por último, buscou-se averiguar, como feito anteriormente, se o critério de rateio do OP de Serra/ES beneficiou, prioritariamente, as regionais onde a proporção de domicílio inadequado é maior. Assim como os demais indicadores utilizados, a proporção de domicílio inadequado indica, de certa forma, a concentração de pobres em um determinado território.

Ao confrontar o investimento per capita do OP distribuído pelas regionais entre os anos de 1998 a 2008, com a proporção de domicílios inadequados, foi identificado uma ausência de correlações entre ambos os indicadores. Observou-se que nenhuma área classificada como de baixo status (último quartil, ou seja, área de maior concentração de domićlios inadequados) recebeu alto investimento per capita, limitando-se o alto investimento per capita às regionais classificadas como alto ou médio alto status social (áreas de menor proporção de domicílios inadequados).

Outro indicador muito utilizado para delimitar as áreas mais carentes é a taxa de analfabetismo entre a população com 15 anos ou mais. Como um dos índices que compõem o critério de rateio engloba esse indicador demográfico, espera-se que as áreas de maior concentração de analfabetos obtenham maior investimento per capita. Ao confrontar (utilizando-se da mesma metodologia) o volume de investimento per capita e a taxa de analfabetismo entre a população com 15 anos ou mais, não ficou evidenciada uma correlação. Mas ficou constatado que, embora não atenda prioritariamente as regionais com elevado percentual de analfabetos, o critério do OP não tem promovido o "princípio de causação circular".

\section{Avaliação do potencial redistri- butivo da deliberação social por meio do Orçamento Participativo de Serra /ES}

O procedimento metodológico da presente seção busca identificar a lógica alocativa dos investimentos do OP pelos bairros, os quais também foram classificados em grupos de status social com base na proporção de chefes de domicílios com renda mensal de até dois salários mínimos. Desta forma busca-se analisar a potencialidade redistributiva da deliberação social, como apresentado no Cartograma 4.

O Cartograma 4 apresenta uma visualização da distribuição dos investimentos per capita do OP (por quartis) sobreposta à classificação dos bairros, em quartis, de acordo com o percentual de chefe de domicílio com renda de até dois salários mínimos. Tal cartograma não aponta indícios de correlação entre bairros com menor ou maior percentual de chefes de domicílio com rendimento de até dois salários mínimos e maior ou menor investimentos do OP no período de 1998 a 2008. A tabela de contingência (Tabela 2) apresenta tal distribuição: 


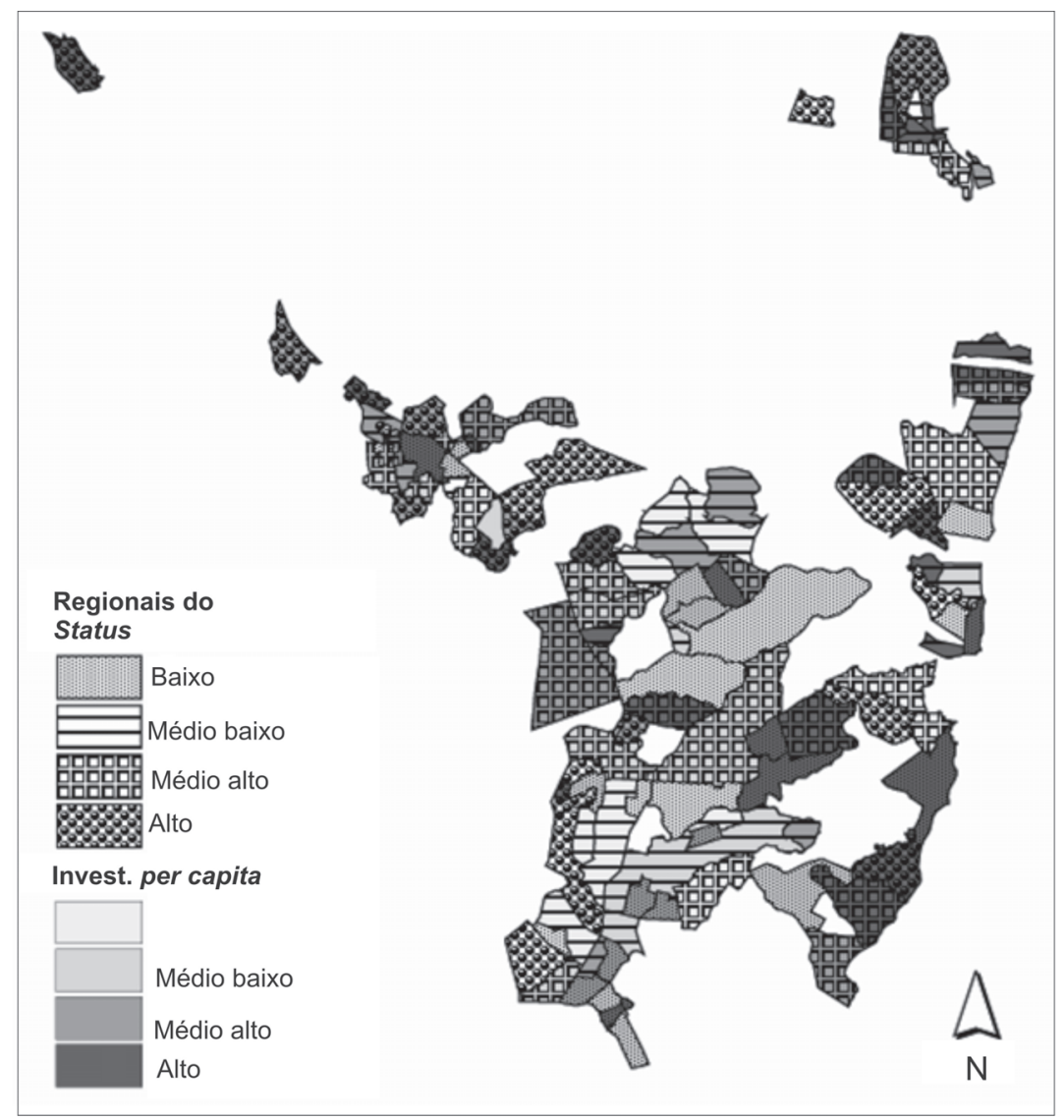

Fonte: Produzido pelo autor a partir da Base de Informações por Setor Censitário do Censo Demográfico (IBGE, 2000) e dados fornecidos pelo Núcleo de Acompanhamento do OP (PMS, 2008; 2011).

Cartograma 4: Serra: Distribuição espacial, por quartis, dos investimentos per capita destinados ao OP (1998 a 2008) e o percentual de chefes de domicílio com renda de até dois salários mínimos (2000), por bairro

Nota-se, a partir da Tabela 2, que não houve um atendimento prioritário a nenhum dos quartis, ou seja, não atende prioritariamente as áreas com maior percentual de chefes de domicílios com renda de até dois salários mínimos (baixo e médio baixo status), o mesmo acorrendo nas áreas onde esse percentual é menor (médio alto e alto status).

Ao analisar a correlação entre maior investimento per capita e percentual de domicílio inadequado (Cartograma 5), constatamos que dos 30 bairros onde a proporção de domicílios inadequados era alta, 10 receberam altos investimentos per capita, assim como quatro deles receberam baixos investimentos per capita. Observou-se que dos 24 bairros com baixa proporção de domicílio inadequado, quatro receberam alto investimento per capita e seis receberam baixo investimento per capita do OP. 
Tabela 2: Tabela de contingência da distribuição, por quartis, dos investimentos per capita destinados ao OP (1998 a 2008) e o percentual de chefes de domicílio com renda de até dois salários mínimos (2000), por bairro

\begin{tabular}{cccccc}
\hline & \multicolumn{3}{c}{$\begin{array}{c}\text { \% chefe de dom. com renda de até } \\
\text { dois salários mínimos }\end{array}$} & \\
\cline { 2 - 5 } $\begin{array}{l}\text { Investimentos } \\
\text { do OP por } \\
\text { quartil }\end{array}$ & Baixo & $\begin{array}{c}\text { Médio } \\
\text { baixo }\end{array}$ & $\begin{array}{c}\text { Médio } \\
\text { alto }\end{array}$ & Alto & \\
\hline Baixo & 6 & 7 & 7 & 7 & $\mathbf{2 7}$ \\
$\begin{array}{c}\text { Médio baixo } \\
\text { Médio alto }\end{array}$ & 8 & 5 & 7 & 7 & $\mathbf{2 7}$ \\
$\quad$ Alto & 8 & 8 & 7 & 7 & $\mathbf{2 7}$ \\
\hline Total & $\mathbf{2 7}$ & $\mathbf{2 7}$ & $\mathbf{2 7}$ & $\mathbf{2 7}$ & $\mathbf{2 8}$ \\
\hline
\end{tabular}

Fonte: Produzido pelo autor a partir da Base de Informações por Setor Censitário do Censo Demográfico (IBGE, 2000) e dados fornecidos pelo Núcleo de Acompanhamento do OP (PMS, 2008).

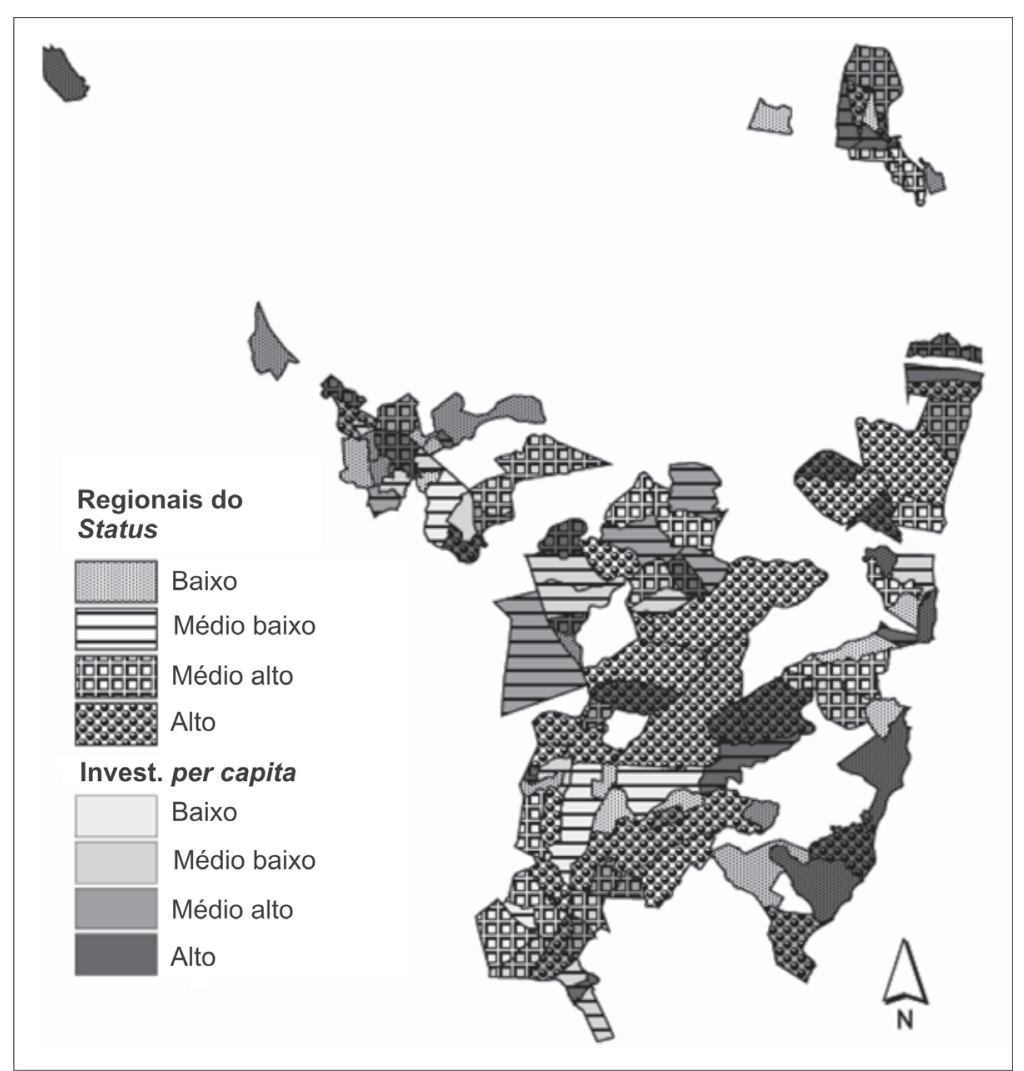

Fonte: Produzido pelo autor a partir da Base de Informações por Setor Censitário do Censo Demográfico (IBGE, 2000) e dados fornecidos pelo Núcleo de Acompanhamento do OP (PMS, 2008).

Cartograma 5: Serra: Distribuição espacial, por quartis, dos investimentos per capita destinados ao OP (1998 a 2008) e o percentual de domicílios inadequados (2000), por bairro 
Por meio da Tabela 3 podemos observar a distribuição dos investimentos per capita pelas áreas, por grupos de quartis de percentuais de domicílios inadequados. Tais resultados são apresentados por meio de uma tabela de contingência.
Notou-se que a espacialização das variáveis sobre a malha urbana de Serra/ ES aponta que a maior parte dos bairros (19 dos 27 bairros) com alta proporção de domicílios com esgoto inadequado (em vermelho) recebeu "alto" ou "médio alto"

Tabela 3: Tabela de contingência da distribuição, por quartis, dos investimentos per capita destinados ao OP (1998 a 2008) e o percentual de domicílios inadequados (2000), por bairro

\begin{tabular}{lrrrrr}
\hline & \multicolumn{4}{c}{$\%$ domicílios inadequados } & \\
\cline { 2 - 5 } $\begin{array}{l}\text { Investimentos } \\
\text { do OP por } \\
\text { quartil }\end{array}$ & Baixo & $\begin{array}{c}\text { Médio } \\
\text { baixo }\end{array}$ & $\begin{array}{c}\text { Médio } \\
\text { alto }\end{array}$ & Alto & \\
Baixo & 6 & 3 & 9 & 9 & $\mathbf{2 7}$ \\
Médio baixo & 6 & 10 & 7 & 4 & $\mathbf{2 7}$ \\
Médio alto & 8 & 6 & 6 & 7 & $\mathbf{2 7}$ \\
Alto & 4 & 6 & 8 & 10 & $\mathbf{2 8}$ \\
\hline Total & $\mathbf{2 4}$ & $\mathbf{2 5}$ & $\mathbf{2 5}$ & $\mathbf{3 0}$ & $\mathbf{1 0 9}$ \\
\hline
\end{tabular}

Fonte: Produzido pelo autor a partir da Base de Informações por Setor Censitário do Censo Demográfico (IBGE, 2000) e dados fornecidos pelo Núcleo de Acompanhamento do OP (PMS, 2008; 2011).

Com base nos resultados apresentados na Tabela 3 observamos que:

- Dos 24 bairros com percentual baixo de domicílios inadequados, 12 deles receberam investimento per capita classificado entre "médio alto" e "alto";

- Dos 30 bairros com alto percentual de domicílios inadequados, 17 deles receberam investimento per capita classificado entre "médio alto" e "alto".

Observamos que existem indícios que apontam que a deliberação social do OP em Serra/ES tem beneficiado mais os bairros de maior proporção de domicílios inadequados.

O Cartograma 6 apresenta análise do investimento per capita correlacionado à proporção de domicílio com esgoto inadequado. investimento per capita do OP durante o período em estudo (ver Tabela 4). Desta forma, pode-se concluir que a deliberação social tem beneficiado preferencialmente os bairros onde a proporção de domicílio com esgoto inadequado é maior.

Ao realizar o mesmo procedimento metodológico referente à taxa de analfabetismo, notou-se que não existe nenhuma lógica correlativa entre as duas variáveis em análise (taxa de analfabetismo e investimentos do OP). Os bairros que receberam alto investimento per capita, por exemplo, não se enquadram predominantemente em nenhum dos grupos de quartis por taxa de analfabetismo.

Dos 27 bairros onde o percentual de analfabetismo era alto, apenas sete receberam altos investimentos per capita, assim 


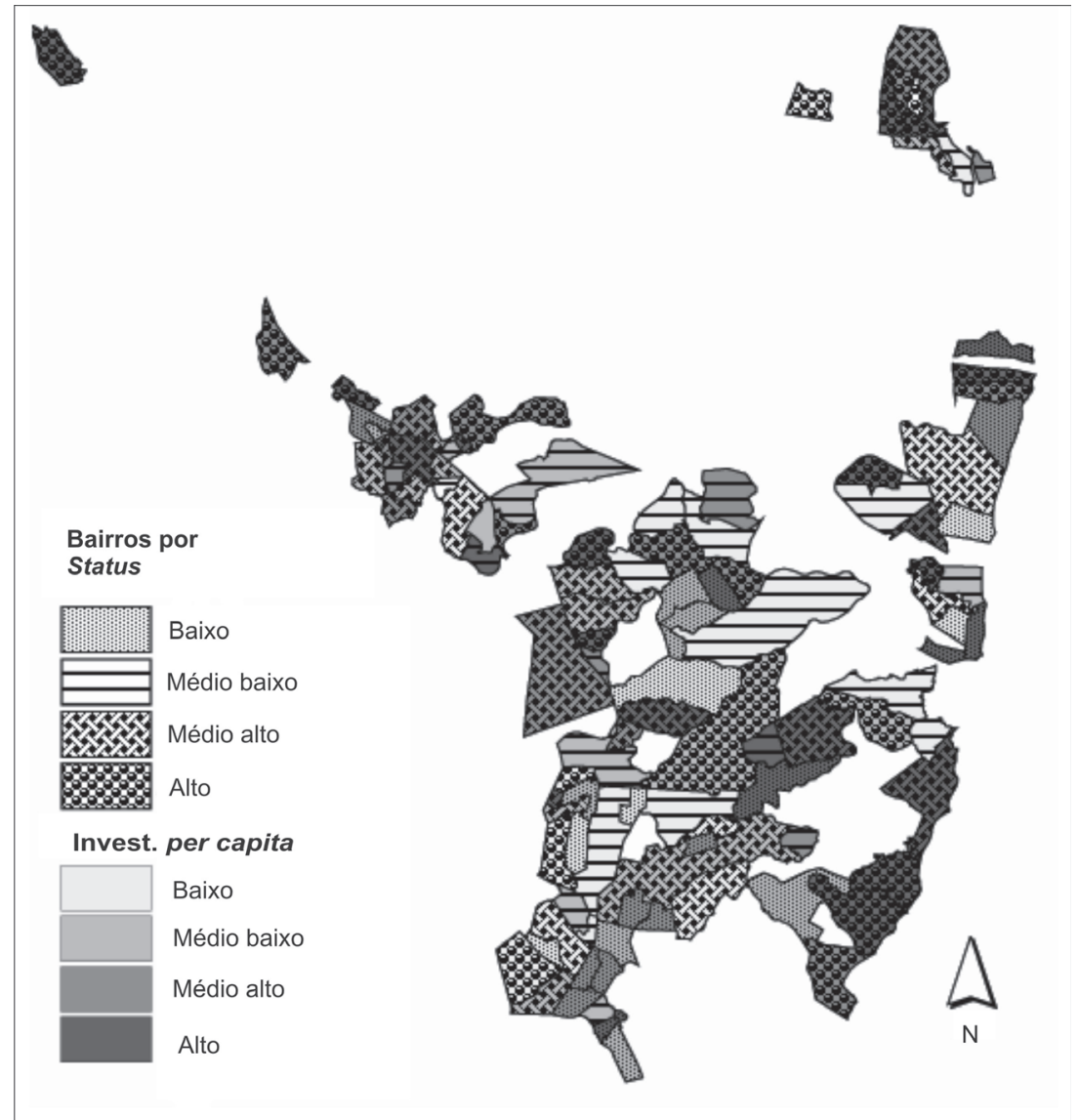

Fonte: Produzido pelo autor a partir da Base de Informações por Setor Censitário do Censo Demográfico (IBGE, 2000) e dados fornecidos pelo Núcleo de Acompanhamento do OP (PMS, 2008; 2011).

Cartograma 6: Serra: Distribuição espacial, por quartis, dos investimentos per capita destinados ao OP (1998 a 2008) e o proporção de domicílio com esgoto inadequado (2000), por bairro

como cinco deles receberam baixos investimentos per capita. Observa-se que dos 27 bairros com baixa taxa de analfabetismo, oito receberam alto investimento per capita e sete receberam baixo investimento per capita do OP, como indica a Tabela 5.

A partir das análises realizadas nesta seção, pode-se afirmar que a prática deliberativa do OP de Serra não tem sido capaz de atender prioritariamente os bairros onde a taxa de chefes de domicílios com renda de até dois salários mínimos era maior (último quartil), assim como não canalizou os investimentos do OP para os bairros com as maiores taxas de analfabetismo. A deliberação social promovida pelo OP de Serra/ES parece ter beneficiado prioritariamente os bairros onde há percentual maior de domicílio e esgoto inadequado. Uma possibilidade de explicar tal correlação pode estar no fato de tratarse de obras destinadas ao saneamento 
Tabela 4: Tabela de contingência da distribuição, por quartis, dos investimentos per capita destinados ao OP (1998 a 2008) e o percentual de domicílios com esgoto inadequado (2000), por bairro

\begin{tabular}{|c|c|c|c|c|c|}
\hline \multirow[b]{2}{*}{$\begin{array}{l}\text { Investimentos } \\
\text { do OP por } \\
\text { quartis }\end{array}$} & \multicolumn{4}{|c|}{$\begin{array}{l}\text { Percentual de domicílios com esgoto } \\
\text { inadequado }\end{array}$} & \multirow[b]{2}{*}{ Total } \\
\hline & Baixo & $\begin{array}{l}\text { Médio } \\
\text { baixo }\end{array}$ & $\begin{array}{l}\text { Médio } \\
\text { alto }\end{array}$ & Alto & \\
\hline Baixo & 6 & 11 & 5 & 5 & 27 \\
\hline Médio baixo & 8 & 7 & 9 & 3 & 27 \\
\hline Médio alto & 8 & 5 & 6 & 8 & 27 \\
\hline Alto & 5 & 4 & 8 & 11 & 28 \\
\hline Total & 27 & 27 & 28 & 27 & 109 \\
\hline
\end{tabular}

Fonte: Produzido pelo autor a partir da Base de Informações por Setor Censitário do Censo Demográfico (IBGE, 2000) e dados fornecidos pelo Núcleo de Acompanhamento do OP (PMS, 2008; 2011).

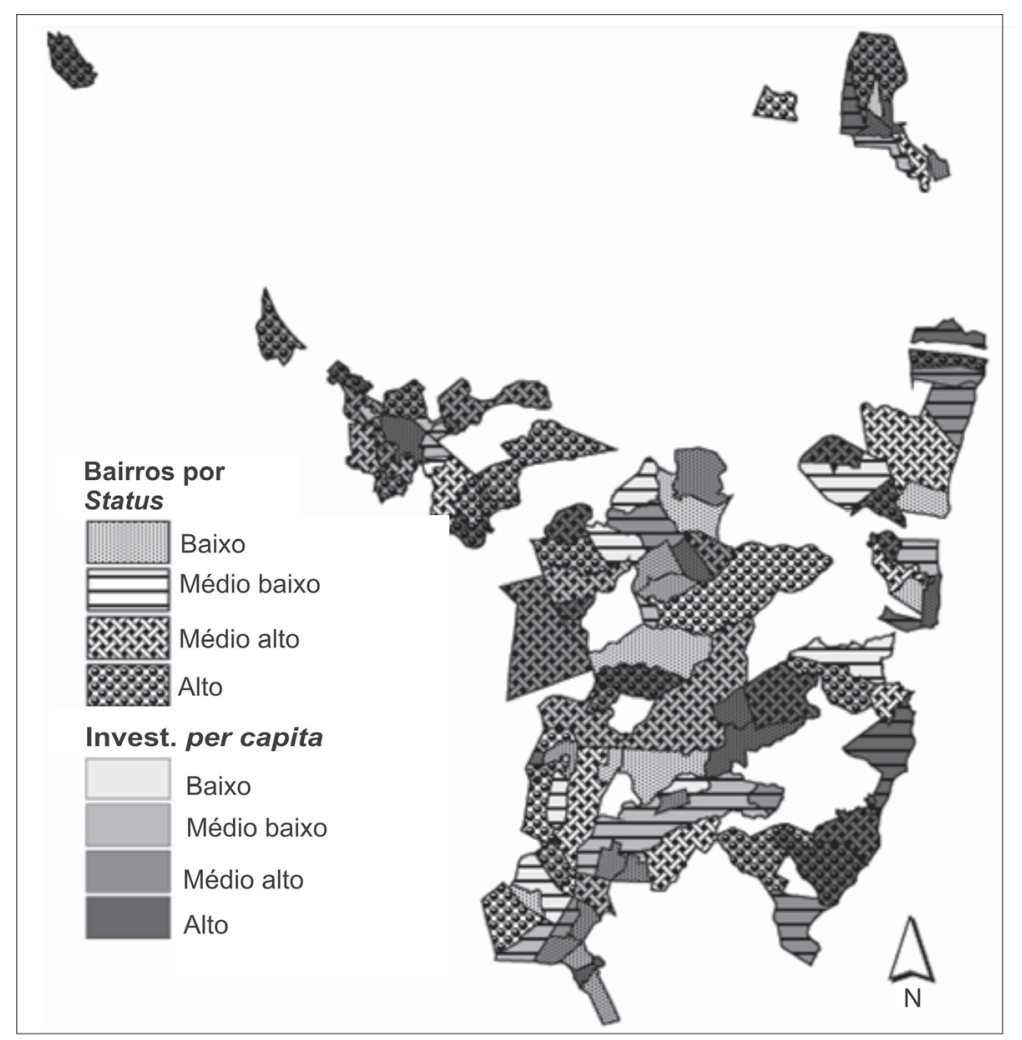

Fonte: Produzido pelo autor a partir da Base de Informações por Setor Censitário do Censo Demográfico (IBGE, 2000) e dados fornecidos pelo Núcleo de Acompanhamento do OP (PMS, 2008; 2011).

Cartograma 7: Serra: Distribuição espacial, por quartis, dos investimentos per capita destinados ao OP (1998 a 2008) e o proporção de analfabetos com 15 anos ou mais (2000), por bairro. 
Tabela 5: Tabela de contingência da distribuição, por quartis, dos investimentos per capita destinados ao OP (1998 a 2008) e o percentual de analfabetos com 15 anos ou mais (2000), por bairro

\begin{tabular}{lrrrrr}
\hline & \multicolumn{3}{c}{ Percentual de analfabetos } & \multirow{2}{*}{ Total } \\
\cline { 2 - 6 } $\begin{array}{l}\text { Investimentos } \\
\text { do OP por } \\
\quad \text { quartis }\end{array}$ & Baixo & $\begin{array}{c}\text { Médio } \\
\text { baixo }\end{array}$ & $\begin{array}{c}\text { Médio } \\
\text { alto }\end{array}$ & Alto & \\
Baixo & 7 & 7 & 8 & 5 & $\mathbf{2 7}$ \\
Médio baixo & 6 & 8 & 5 & 7 & $\mathbf{2 6}$ \\
Médio alto & 6 & 6 & 7 & 8 & $\mathbf{2 7}$ \\
Alto & 8 & 6 & 7 & 7 & $\mathbf{2 8}$ \\
\hline Total & $\mathbf{2 7}$ & $\mathbf{2 7}$ & $\mathbf{2 7}$ & $\mathbf{2 7}$ & $\mathbf{1 0 8}$ \\
\hline
\end{tabular}

Fonte: Produzido pelo autor a partir da Base de Informações por Setor Censitário do Censo Demográfico (IBGE, 2000) e dados fornecidos pelo Núcleo de Acompanhamento do OP (PMS, 2008; 2011).

básico, as quais geralmente consomem grandes volumes de investimentos públicos, assim como tratar-se das áreas urbanas mais carentes de obras que melhorem a aparência desses bairros.

Este trabalho, em síntese, nos forneceu alguns resultados, os quais são apresentados na Tabela 6.

A Tabela 6 permite a formação de uma visão geral dos resultados alcançados, deixando claro o potencial do critério de rateio do orçamento participativo de Serra/ES e da deliberação social realizada no período em análise.

\section{Considerações finais}

A produção do espaço urbano pela ação direta do poder público é apontada por diversos autores como clientelística, concretizando o que ficou conhecido como "princípio de causação circular", onde as áreas de alto status vêm sendo historicamente as mais beneficiadas pela ação do poder público, especialmente por meio de obras de infraestrutura. As práticas de orçamentos participativos têm sido apontadas como ações capazes de promover o rompimento com tal princípio, assim como ser um instrumento de redistribuição de renda real.

Neste artigo foram analisados separadamente o instrumento de rateio do OP e a deliberação social, ambos praticados em Serra/ES por meio do Orçamento Participativo. Objetivo central foi identificar se o critério de rateio do OP de Serra e a deliberação social sobre os investimentos em obras de infraestrutura têm sido capazes de romper com o "princípio de causação circular" e promover redistribuição de renda real. Ao longo das análises em torno da distribuição dos investimentos per capita em obra de infraestrutura destinados ao OP de Serra/ES, a partir do critério técnico de rateio, foi possível identificar que não tem beneficiado prioritariamente as áreas de baixo status, quando essas são classificadas a partir do percentual de chefes de domicílios com renda de até dois salários mínimos ou das taxas de analfabetismo, mas tem sido capaz de romper com o "princípio de causação circular". 
Tabela 6: Resumo dos resultados encontrados a partir do estudo de caso: alocação dos investimentos do OP (1998 a 2008) e o princípio de causação circular

\begin{tabular}{|c|c|c|c|c|}
\hline $\begin{array}{l}\text { Relação do investimento } \\
\text { per capita do OP com: }\end{array}$ & $\begin{array}{c}\text { Critério de rateio } \\
\text { pelas regionais }\end{array}$ & $\begin{array}{l}\text { Princípio } \\
\text { de } \\
\text { causação } \\
\text { circular? }\end{array}$ & $\begin{array}{l}\text { Deliberação social } \\
\text { pelos bairros }\end{array}$ & $\begin{array}{l}\text { Princípio } \\
\text { de } \\
\text { causação } \\
\text { circular? }\end{array}$ \\
\hline $\begin{array}{l}\text { Percentual de chefes de } \\
\text { domicílio com renda de até } \\
\text { dois salários mínimos }\end{array}$ & $\begin{array}{c}\text { Maior parte dos } \\
\text { investimentos para as } \\
\text { áreas de baixo e médio } \\
\text { baixo status. }\end{array}$ & Não & $\begin{array}{c}\text { Não houve } \\
\text { atendimento } \\
\text { prioritário a nenhum } \\
\text { dos grupos de } \\
\text { quartis }\end{array}$ & Não \\
\hline $\begin{array}{l}\text { Proporção de domicílios } \\
\text { com esgoto inadequado }\end{array}$ & $\begin{array}{c}\text { Maior parte dos } \\
\text { investimentos para as } \\
\text { áreas de baixo e médio } \\
\text { baixo status }\end{array}$ & Não & $\begin{array}{l}\text { Beneficiados } \\
\text { preferencialmente } \\
\text { os bairros onde a } \\
\text { proporção de } \\
\text { domicílio com } \\
\text { esgoto inadequado } \\
\text { era maior. }\end{array}$ & Não \\
\hline $\begin{array}{l}\text { Proporção de domicílios } \\
\text { inadequados }\end{array}$ & $\begin{array}{l}\text { Maior parte dos } \\
\text { investimentos para as } \\
\text { áreas de menor } \\
\text { proporção de } \\
\text { domićlíios } \\
\text { inadequados }\end{array}$ & $\mathrm{Sim}$ & $\begin{array}{l}\text { Maior } \\
\text { beneficiamento dos } \\
\text { bairros de maior } \\
\text { proporção de } \\
\text { domicílios } \\
\text { inadequados. }\end{array}$ & Não \\
\hline Proporção de analfabetos & $\begin{array}{l}\text { Maior parte dos } \\
\text { investimentos para } \\
\text { áreas de médio baixo e } \\
\text { médio alto status. }\end{array}$ & Não & $\begin{array}{l}\text { Não se enquadram } \\
\text { predominantemente } \\
\text { em nenhum dos } \\
\text { grupos de quartis } \\
\text { por taxa de } \\
\text { analfabetismo. }\end{array}$ & Não \\
\hline
\end{tabular}

Fonte: Produzido pelo autor a partir da Base de Informações por Setor Censitário do Censo Demográfico (IBGE, 2000) e dados fornecidos pelo Núcleo de Acompanhamento do OP (PMS, 2008; 2011).

Identificamos que na prática de OP em Serra existem indícios de correlação entre investimento per capita do OP e proporção de domićlilios inadequados e/ou com esgoto inadequado. Uma hipótese para tal correlação pode estar no fato de tratar-se de obras destinadas ao saneamento básico, as quais geralmente consomem grandes volumes de investimentos públicos, assim como de serem áreas, devido aos domicílios inadequados, visivelmente mais carentes do município.

Finalmente, o OP de Serra/ES tem sido capaz de romper com o "princípio de causação circular”, embora não tenha atendido prioritariamente as áreas de baixa renda ou as áreas com maiores taxas de analfabetismo. A partir deste trabalho, embora tendo um objeto de estudo pontual e particular, é possível concluir que práticas de gestão pública como o orçamento participativo podem ser um caminho para a produção de um espaço urbano mais justo, uma vez que tal instrumento parece não permitir que a lógica alocativa identificada por Terra (2007), em Campos dos Goytacazes, e por Vetter, Massena e Rodrigues (1979), no Rio de Janeiro, fosse observada em Serra/ES.

(Artigo recebido em maio de 2010. Versão final em abril de 2011). 


\section{Notas}

* Este artigo é parte da dissertação de mestrado defendida em outubro de 2009 no programa de Mestrado em Planejamento Regional e Gestão de Cidade da Universidade Candido Mendes/ Campos, RJ, tendo como orientadora Dr ${ }^{a}$ Denise Cunha Tavares Terra.

1 Grosso modo, a "causação circular" trata-se de um princípio marcado pelo beneficiamento prioritário de áreas já beneficiadas anteriormente ou áreas de alto status social.

2 De forma resumida pode-se dizer que para Harvey os "mecanismos ocultos" da redistribuição de rendas são as ações locacionais de investimentos públicos ou privados, que consequentemente ampliam ou reduzem a renda real dos indivíduos.

3 Nos cartogramas são apresentadas apenas as áreas consideradas pelo IBGE, em 2000, como urbanas. Os vazios são áreas rurais ou não ocupadas devido ao grande número de áreas alagadiças e de rochedos.

4 Tais indicadores foram obtidos a partir de dados do Censo Demográfico 2000 (IBGE, 2004).

5 Salário mínimo de $\mathrm{R} \$ 151,00$, referente ao período do censo demográfico de 2000.

6 Foram considerados domicílios inadequados as unidades de habitação em cômodo ou improvisado.

7 Foram considerados como sistema de esgoto inadequado aqueles domicílios que não possuíam ligação com rede geral de esgoto ou fossa séptica.

8 O ArcView 3.2 trata-se de um software de SIG (Sistema de Informações Geográficas) que permite visualizar, produzir ou manipular dados de componentes geográficos.

9 O termo "região" ou "regional", utilizado neste artigo, se refere à regionalização baseada no agrupamento de bairros da cidade para a distribuição (entre as regiões) dos valores destinados ao OP. Desta forma, se trata de uma região administrativa composta por diversos bairros da cidade, a fim de facilitar a prática do OP.

${ }^{10}$ Dados também disponíveis no site da Prefeitura Municipal de Serra/ES.: < http:// www.serra.es.gov.br/portal_pms $/$ site.do?evento $=$ x\&lang $=\&$ \&idConteudo $=5620 \& \mathrm{chPlc}=5620 \& \mathrm{pg}=$ 5001\&taxp=0\&lang=pt_BR $>$ Acessado em: Março de 2011.

\section{Referências bibliográficas}

Amo. Assembleia Municipal do Orçamento. Serra/ES. Documentos avulsos.

Azevedo, Neimar Duarte. A face representativa do orçamento participativo. In: AzEvedo, Sergio de; Fernandes, Rodrigo Barroso. Orçamento Participativo: construindo a democracia. Rio de Janeiro: Revan, 2005.

Avritzer, Leonardo (Org). A Participação social no Nordeste. Belo Horizonte: Editora UFMG, 2007.

Avritzer, Leonardo; Navarro, Zander (Org.). A inovação democrática no Brasil. São Paulo: Cortez, 2003. 
O Orçamento Participativo e a teoria democrática: um balanço crítico. In: Avritzer, Leonardo; Navarro, Zander (Org.). A inovação democrática no Brasil. São Paulo: Cortez, 2003.

BOAs, Marie-Hélène Sa Vilas. A participação como recurso disputado: uma análise dos dispositivos participativos dirigidos às mulheres introduzidas em Recife. In: DAGNINO, Evelina; Tatagiba, Luciana (Org.). Democracia, sociedade covil e participação. Chapecó: Argos, 2007.

Campos, Geraldo Adriano. Orçamento Participativo de São Paulo: limiar da participação e redistribuição na metrópole. In: MARquetTi, Aldamir; CAMPos, Geraldo Adriano de; PIREs, Roberto (Org.). Democracia Participativa e Redistribuição: análise de experiências do orçamento participativo. São Paulo: Xamã, 2008.

Carlos, Euzinéia. Controle Social e Política Redistributiva no Orçamento Participativo. Vitória: EDUFES, 2007.

CoÊLHo, Denílson Bandeira. Gestão municipal e arranjos participativos em Pernambuco: entre racionalidade política e ajustes distributivos. In: Avritzer, Leonardo (Org). A Participação social no Nordeste. Belo Horizonte: Editora UFMG, 2007.

CorrêA, Roberto Lobato Corrêa. O Espaço Urbano. 2a ed. São Paulo: Ática, 1993.

Trajetórias geográficas. $3^{\mathrm{a}}$ ed. Rio de Janeiro: Bertrand Brasil, 2005,

Correia, Claudia. Gestão Democrática da Cidade: construindo uma nova política. In: Ribeiro, Luiz César de Queiroz; Cardoso, Adauto Lucio. Reforma Urbana e Gestão Democrática: promessas e desafios do Estatuto da Cidade. Rio de Janeiro: Revan, 2003.

CunHA, Eleonora Shettini Martins. O potencial de conselhos de políticas e orçamentos participativos para o aprofundamento democrático. In: DAgnino, Evelina; TATAgiBa, Luciana (Org.). Democracia, sociedade covil e participação. Chapecó: Argos, 2007.

FAms. Federação das Associações de Moradores da Serra/ES. Documentos avulsos.

Futura. Anuário de Finanças dos Municípios Capixabas. 2008. Disponível em: http:// www.aequus.com.br/anuarios/capixabas_2008/ Acessado em: 20 de Março de 2011. Gugliano, Alfredo Alejandro. Processos Participativos de gestão pública em Porto Alegre e Montevidéu: comparando semelhanças e diferenças. In: DAGnino, Evelina; Tatagiba, Luciana (Org.). Democracia, sociedade covil e participação. Chapecó: Argos, 2007. Harvey, David. Justiça Social e a Cidade. São Paulo: Hucitec, 1980.

Innni. Otávio. Capitalismo, Violência e Terrorismo. Rio de Janeiro: Civilização Brasileira, 2004.

IBGE. Instituto Brasileiro de Geografia e Estatística. Censo Demográfico. Brasil, 2000.

MARQues, Eduardo César. Redes sociais e poder no Estado brasileiro: aprendizados a partir de políticas urbanas. Revista brasileira de Ciências Sociais, São Paulo, v. 21, nº0, fev. de 2006.

Marquetti, Aldamir. Experiências de Orçamento Participativo no Brasil: uma proposta de classificação. In: Dagnino, Evelina; Tatagiba, Luciana (Org.). Democracia, sociedade covil e participação. Chapecó: Argos, 2007.

Marquettr, Aldamir; Campos, Geraldo Adriano de; Pires, Roberto (Org.). Democracia Participativa e Redistribuição: análise de experiências do orçamento participativo. São Paulo: Xamã, 2008. 
Mingheldi, Marcelo. Orçamento Participativo: uma leitura jurídico-política. Canoas: UlBRA, 2005.

Myrdal, Gunnar. Teoria econômica e regiões subdesenvolvidas. Tradução de N. Palhano. Rio de Janeiro: Editora Saga, 1968.

Pereira, Marcus Abílio Gomes. Modelos democráticos deliberativos e participativos: similitudes, diferenças e desafios. In: Dagnino, Evelina; Tatagiba, Luciana (Org.). Democracia, sociedade covil e participação. Chapecó: Argos, 2007.

Pires, Roberto. Aspectos regulamentação da participação no OP em Belo Horizonte: eficiência distributiva aliada ao planejamento urbano. In: MARQUeTti, Aldamir; CAMPOS, Geraldo Adriano de; PIREs, Roberto (Org.). Democracia Participativa e Redistribuição: análise de experiências do orçamento participativo. São Paulo: Xamã, 2008. Prefeitura Municipal da Serra/ES. Secretaria de Finanças.

Serra. Agenda 21, Estudo Temático: vetores de desenvolvimento e dinâmica populacional da Serra. Serra: Prefeitura Municipal da Serra/ES, volume I, 2000.

SERra. Agenda 21, Estudo Temático: Espaço Urbano, Habitação e uso do solo. Serra/ES: Prefeitura Municipal da Serra, volume V, 2000 b.

SErra. Perfil Socioeconômico. Serra: Prefeitura Municipal da Serra, 2007.

Serra. Balanços Municipais. Serra: Prefeitura Municipal da Serra, 2008.

Souza, Marcelo Lopes de. A Prisão e a Ágora: reflexões em torno da democratização do planejamento e da gestão das cidades. Rio de Janeiro: Bertrand Brasil, 2006.

Teixeira, Ana Cláudia Chaves. O OP em pequenos municípios rurais: contextos, condições de implementação e formatos de experiências. In: AvritZER, Leonardo; NAvArro, Zander (Org.). A inovação democrática no Brasil. São Paulo: Cortez, 2003.

Terra, Denise Cunha Tavares. Uma leitura espacial da apropriação desigual das rendas petroliferas em Campos dos Goytacazes. 2007. Tese (Doutorado). UFRJ/PPGG, Rio de janeiro. Vetter, David Michael; Massena, Rosa Maria. Quem se apropria dos Benefícios Líquidos dos investimentos do Estado em Infraestrutura Urbana? Uma teoria da causação circular. In: SiLVA, L. A. Machado (org). Solo Urbano: tópicos sobre o uso da terra. Rio de Janeiro: Zahar Editores, 1981.

Vetter, David Michael; Massena, Rosa Maria e Rodrigues, Elza Freire. Espaço, valor da terra e eqüidade dos investimentos em infra-estrutura do município do Rio de Janeiro. In: Revista Brasileira de Geografia, Rio de Janeiro, v. 41, n 1-2, p. 32-71, jan./jun. 1979. VetTer, David Michael; Pinto, Dulce Maria Alcides; Friedrich, Olga Buarque de Lima; Massena, Rosa Maria Ramalho. A apropriação dos benefícios das ações do Estado em áreas urbanas: seus determinantes e análise através de ecologia fatorial. Temas Urbanos, Revista Espaço e Debates, no 4, p. 5-37, 1981. 


\section{Resumo-Resumen-Abstract}

\section{Estudo socioterritorial e investimentos públicos: o processo de alocação de recursos do orçamento participativo em Serra/ES \\ Cristiano das Neves Bodart}

O presente artigo busca, a partir de um estudo de caso, identificar se o Orçamento Participativo (OP) tem sido instrumento de gestão pública capaz de mitigar as desigualdades socioespaciais, rompendo com o "princípio de causação circular", este caracterizado como o beneficiamento prioritário de áreas de alto status social a partir da ação do poder público por meio de obras de infraestrutura. $O$ estudo está centrado na prática do OP realizado no município de Serra/ES (1997 - 2008). Além da fundamentação teórica, a metodologia utilizada baseou-se, inicialmente, em caracterizar os espaços urbanos de Serra, a partir de indicadores selecionados, em áreas de status social, para posteriormente identificar a lógica alocativa dos valores destinados às obras de infraestrutura urbanas diretamente ligadas ao OP. Foi constatado que a prática do OP, no referido município, tem sido capaz de romper com o "princípio de causação circular”, embora não tenha atendido prioritariamente as áreas urbanas onde existe uma maior proporção de analfabetos e chefes de domicílio com renda de até dois salários mínimos.

Palavras-Chave: Orçamento participativo; deliberação social; alocação de obras públicas; desigualdade socioespacial

\section{Estudio socioterritorial de inversiones públicas: el proceso de asignación de recursos del presupuesto parcipativo en Sierra/ES \\ Cristiano das Neves Bodart}

Este artículo pretende, a partir de un estudio de caso, determinar si el Presupuesto Participativo (PP) ha sido un instrumento de la gestión pública capaz de mitigar la situación socioespacial, rompiendo con el "principio de causalidad circular", principio caracterizado como procesamiento prioritario de las áreas de alto status social por acciones de poderes públicos a través de obras de infraestructura. El estudio se centra en la práctica del PP en el municipio de Serra / ES (1997 - 2008). Además de los antecedentes teóricos, la metodología se basó, inicialmente, en caracterizar los espacios de Serra, sobre la base de los indicadores seleccionados, en las zonas de estatus social para identificar posteriormente la lógica de reparto de los importes asignados a los proyectos de infraestructura urbana directamente relacionados con el PP. Se señaló que el PP, en este municipio, ha sido capaz de romper con el "principio de causalidad circular", aunque no ha servido principalmente las zonas urbanas donde hay una mayor proporción de analfabetos y cabezas de domicilios con ingresos de hasta dos salarios mínimos.

Palabras Clave: Presupuesto participativo, deliberación social, asignación de obras públicas, desigualdad socioespacial

\section{Study and territorial social and public investments: the process of allocation of resources budgeting in Sierra/ES \\ Cristiano das Neves Bodart}

The present article seeks, from the basis of a case study, to identify whether Participatory Budgeting has been an instrument of public administration capable of mitigating socio-spatial inequalities, breaking with the "principle of circular causation," this principle characterized as the priority improvement of areas of high social status from the action of government by means of infrastructure. The study is centered on the practice of PB carried out in the municipality of Serra, ES 
(1997 - 2008). Apart from the theoretical background, the methodology utilized was initially based on characterizing urban spaces of Serra, using selected indicators, in areas of social status in order to further identify the allocative logic of values destined for urban works of infrastructure directly tied to PB. It was found that the practice of PB in the cited municipality was able to break with the "principle of circular causation," although it has not served primarily urban areas where there is a higher proportion of illiterate persons and heads of households with incomes of up to two minimum wages.

Keywords: Participatory budgeting; social deliberation; allocation of public works; socio-spatial inequality

Cristiano das Neves Bodart

Mestre em Planejamento Regional e Gestão de Cidades pela Universidade Candido Mendes (UCAM) e Cientista

Social. Contato: cristianobodart@hotmail.com 